Journal of Thermal Engineering, Vol. 6, No. 1, pp. 157-169, January, 2020

Yildiz Technical University Press, Istanbul, Turkey

\title{
THERMAL ANALYSIS ON VARIABLE THICKNESS ABSORBER PLATE FIN IN FLAT- PLATE SOLAR COLLECTORS USING DIFFERENTIAL TRANSFORM METHOD
}

\author{
Jaideep Dutta ${ }^{1,2}$, Balaram Kundu ${ }^{1, *}$
}

\begin{abstract}
This article highlights a parametric investigation of the thermal analysis of variable thickness flat plate solar collector. Triangular profile of an absorber plate has been adopted from the point of view of saving in material. An approximate analytical model based on the Taylor series of expansion has been implemented for finding out the temperature distribution in the heat conduction direction of the absorber plate. Differential transform method (DTM) has been used to establish a new analytical formulation. The Modified Bessel's function has been applied for the comparison of the results produced by DTM. The variation of several temperature dependent parameters is studied for knowing the dependency effect. The efficiency of absorber plate has been analysed as a function of Biot number and the impact of aspect ratio on the plate performance has been highlighted. The present analytical approach has ability to determine the thermal performance of an absorber plate under an actual design condition with a minor modification of the analysis. The formulation of the present work is also suitable for the analysis of any shape of an absorber plate in flat-plate solar collectors.
\end{abstract}

Keywords: Absorber Plate, Analysis, DTM, Solar Collector, Variable Plate Thickness

\section{INTRODUCTION}

From past thirty years energy sector have shown immense interest in renewable energy resources due to constant depletion of conventional energy sources for higher consumption of energy. Among the available renewable energy resources solar energy is highly demandable due to its abundance and ease of capturing. Solar energy can be tapped by two ways, i.e., by PV cells and with solar collectors. The absorbed solar energy in collects is used in so many applications. Among the available types of solar collectors, flat plate collectors are very simple to utilize due to simplicity in their design. Basically the solar collector absorbs the incoming solar radiation, converts it into heat and transfers to the transport medium in the tubes for carrying useful energy. The absorber plate in the collector acts as a principal component and it is usually a metal strip. The performance of solar collector is dependent upon the thermophysical properties and design considerations of absorber plate. Flat plate solar collectors are commonly found in domestic hot water, space heating and industrial heating, vapour absorption and air conditioning system [1], etc.

A large number of research works have been devoted for the improvement of performance and design of absorber plate, both mathematically and experimentally. Hollands and Stedman [2] have investigated optimization studies of an absorber plate fin having a step change in local thickness. Ong [3, 4] have provided an important research work where mathematical model has been established for solar air heaters and a comparison has been carried out with experimental results for entire thermal performance. Kundu [5] has modified the analysis provided by Hollands and Stedman [2] with adopting an appropriate boundary condition. He established a generalized analysis for optimum design of plate absorber fin with a constraint of either rate of heat transfer or fin volume. Dhariwala and Mridha [6] proposed analytical expressions for the thermal performance of flat plate solar collector on the basis of transient response. Viorel [7] implemented optimization techniques for size and structure of solar collection systems. The Thermal performance of cross-corrugated and flat plate solar air heaters on the basis of experimental work and analytical studies have been investigated by Gao et al. [8]. An analytical model thermal analysis of absorber plate fin for a new profile viz. recto-trapezoidal on the basis of fabrication as well as heat transfer augmentation has been

This paper was recommended for publication in revised form by Regional Editor Sandip Kale

${ }^{1}$ Dept. of Mech. Eng., Jadavpur University, Raja S. C. Mallick Road, Kolkata - 700032, West Bengal, India

${ }^{2}$ Dept. of Mech. Eng., MCKV Institute of Engineering, 243, G. T. Road (N), Liluah, Howrah - 711204, West Bengal, India

*E-mail address: bkundu@mech.net.in

Orcid id: 0000-0002-5943-7763, 0000-0002-3216-2202

Manuscript Received 11 January 2018, Accepted 14 March 2018 
developed by Kundu [9]. Ho et al. [10] studied the influence of recycle of baffled double pass flat plate solar air heaters where internal fins have been attached. Kundu [11] proposed a decomposition method to find out thermal performance and optimization of an absorber plate fin having variable thermal conductivity and overall loss coefficient. El-Sebaii et al. [12] have carried out analysis of temperature dependent thermal properties of double pass finned plate solar air heater. Kundu and Lee [13] presented analytical techniques for both Fourier's and non-Fourier's heat conduction in an absorber plate of flat plate solar collector by implementing separation of variables. Also a numerical scheme has been utilized for validating the temperature models. Subiantoro and Tiow [14] have depicted analytical model for the prediction of heat loss from the top cover of single and double glazing flat plate solar collectors and the results have been compared with the 2-D CFD analysis. Bracamonte and Baritto [15] have developed a dimensional model of thermal behaviour of flat plate solar collector without glass cover by an entropy balance equation. Also this model was validated for a wide range of aspect ratios. Eismann [16] derived an analytical analysis of flat plate solar collector by using established correlation of Hollands [2] and extended the correlation for convective heat loss across the air gap between absorber and cover plate. Sun et al. [17] illustrated a mathematical model based on the numerical finite difference approach under forced convection mode for a flat plate solar air collector and the model has been validated by an indoor experimental system. Diego-Ayala and Carrillo [18] presented a handful research work by the experimental analysis of temperature and efficiency in terms of mass flow in a flat plate solar collector working under real operating conditions in a hot sub-humid region in the city of Merida, Mexico.

The major advantages of triangular flat plate collectors would be less requirement of material for the same energy transferred rate and hence, the cost of material would be less in comparison with other geometric shapes, like rectangular, trapezoidal, etc. We haven’t found any research papers (from author's best knowledge) for triangular flat plate collector. This has been motivated to carry out the present research work. An effort has been devoted to have a detailed thermal analysis of absorber plate of triangular profile for a flat plate solar collector. The solution has been carried out by implementing Differential Transformation Method (DTM). To validate the analytical method the modified Bessel's function has been employed. Finally a comparative study has been produced to examine different temperature dependent parameters. An exact matching of results has been found and it indicates the successful implementation of DTM in the present study to analyse a flat-plate solar collector.

\section{MATHEMATICAL FORMULATION}

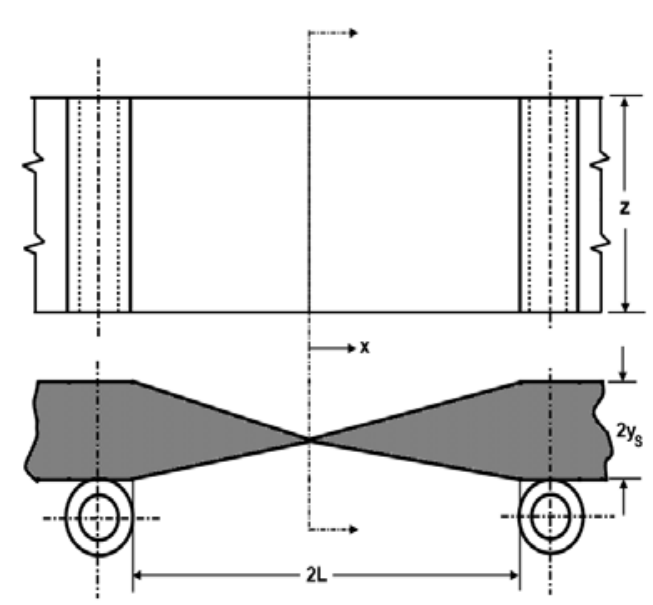

(a)

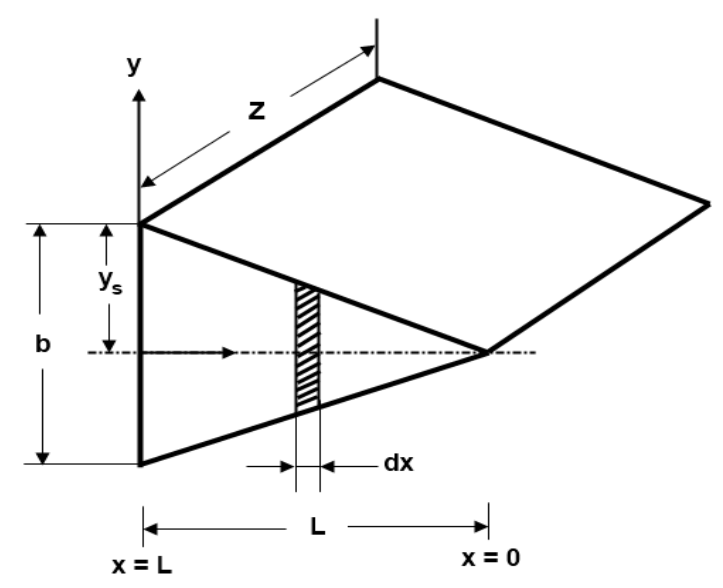

(b)

Figure 1. (a) Schematic diagram of triangular flat plate solar collector module and (b) Schematic diagram of triangular shape for present research analysis 
As conduction heat transfer takes place in the absorber plate, a symmetrical sector can be considered to determine the temperature field. The solar energy is absorbed in the plate and hence the temperature of the plate increases. As the temperature of the plate is higher than the surroundings, heat loss is always present between the absorber plate and the surroundings. However, the energy loss is minimized to have an appropriate design aspect of a flat-plate solar collector and therefore the overall loss coefficient is also less. This overall heat loss coefficient can be taken a constant. The following assumptions have been considered for establishing mathematical model for a triangular shaped absorber plate for varying the thickness of the plate:

- Heat conduction is one dimensional and steady state.

- Temperature changes only along the direction of heat flow in the plate.

- Overall loss coefficient is a constant.

- Thermal conductivity of the plate is assumed to be constant.

- The end effect of the absorber plate is neglected.

- Cross sectional area diminishes in the heat flow direction.

The energy equation of the absorber plate for the current research work can be expressed as follows [19]:

$$
\frac{d}{d x}\left[x \frac{d T}{d x}\right]=\frac{L}{k y_{S}} U_{L} \sqrt{1+\left(\frac{y_{S}}{L}\right)^{2}}\left(T-T_{0}-\frac{S}{2 U_{L}}\right)
$$

where ' $k$ ' is the thermal conductivity of the absorber plate and it is assumed to be constant due to a low temperature variation of the absorber plate. ' $U_{\mathrm{L}}$ ' is the overall loss coefficient and ' $\mathrm{S}$ ' is the absorbed solar radiation on the plate. For the entire flat plate collector temperature rise may not be too high, thus the thermophysical properties can be kept constant. Therefore, Eq. (1) can be written in non-dimensional form as follows:

$$
\frac{d}{d X}\left[X \frac{d \theta}{d X}\right]-P^{2} \theta=0
$$

where,

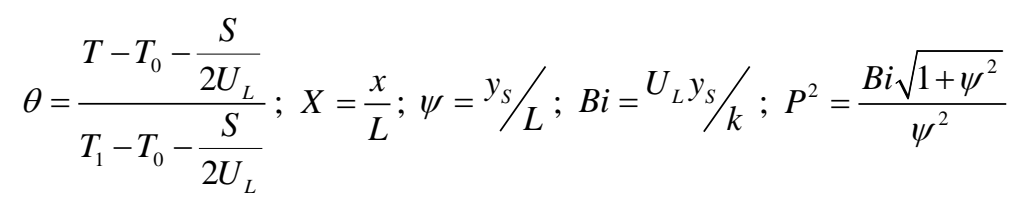

To analyze the temperature distribution of triangular absorber plate, the following boundary conditions are implemented for current model as one symmetric heat transfer module taken:

$$
\begin{aligned}
& \text { At } X=0: \frac{d \theta}{d X}=0 \\
& \text { At } X=1: \theta=1
\end{aligned}
$$

\section{PRINCIPLE OF DIFFERENTIAL TRANSFORMATION METHOD (DTM)}

Ordinary differential equations are generally solved by integral transformation method such as Laplace or Fourier's transformation method. Basically these transformation methods convert the differential equation into corresponding algebraic equation. But it is very tedious to solve a non-linear equation by such integral techniques. However, for this case Differential transformation method (DTM) is ideal. It is a semi-analytical method for solving such non-linear problems. The concept of DTM was first proposed by Zhou [20] and it was used to solve linear as well as non-linear Boundary Value Problems (BVP). The major benefit of this technique is that it can be directly 
employed to linear and non-linear differential equations without perturbation, linearization or discretization. Several important research works on non-linear systems with the help of DTM have been carried out [21-24]. Kundu and Lee [24] have established a new analytical technique based on DTM to determine the heat transfer rate in annular step fins under internal heat generation condition. Yaghoobi and Torabi [25] presented a wonderful research work where two non-linear heat transfer equations subject to variable specific heat have been solved by DTM and the results were compared with Homotopy perturbation method (HPM). Dogonchi and Ganji [26] studied the convectionradiation heat transfer aspects of moving fin with temperature dependent parameters along with the consideration of heat generation by employing DTM.

To understand the basic concept of DTM, let us assume $x(t)$ be analytic in domain D and $t=t_{i}$ denotes any point in that domain. The function $x(t)$ is then represented by a power series whose centre is located at $t_{i}$. The Taylor's series expansion of function $x(t)$ can be expressed as follows:

$$
x(t)=\sum_{i=0}^{\infty} \frac{\left(t-t_{i}\right)^{i}}{i !}\left[\frac{d^{i} x(t)}{d t^{i}}\right]_{t=t_{i}}
$$

Eq. (6) can be converted into Maclaurin series of $x(t)$ by considering $t_{i}=0$ as:

$$
x(t)=\sum_{i=0}^{\infty} \frac{t^{i}}{i !}\left[\frac{d^{i} x(t)}{d t^{i}}\right]_{t=0}
$$

As suggested by Zhou [20] the differential transformation of function $x(t)$ is defined as follows:

$$
X(i)=\sum_{i=0}^{\infty} \frac{H^{i}}{i !}\left[\frac{d^{i} x(t)}{d t^{i}}\right]_{t=0}
$$

where $X(i)$ represents the transformed function of original function $x(t)$. The differential spectrum of $X(i)$ is confined within the interval of $t \in[0, H]$. Here ' $\mathrm{H}$ ' is a constant and it can be assumed as unity in common structure of single step DTM. The information regarding the range of ' $\mathrm{H}$ ' has been discussed elaborately in [27]. Now inverse differential transformation of $X(i)$ can be defined as follows:

$$
x(t)=\sum_{i=0}^{\infty}\left[\frac{t}{H}\right]^{i} X(i)
$$

The valued of transformed function $X(i)$ at different values of argument i are referred to as discrete i.e., $X(0)$ is termed as zero discrete, $X(1)$ as the first discrete and so on. The function $x(t)$ contains T-function of $X(i)$ and its value is given by the summation of T-function with $\left[\frac{t}{H}\right]^{i}$. For the finite series, the function $x(t)$ can finally be written as follows:

$$
x(t)=\sum_{i=0}^{n}\left[\frac{t}{H}\right]^{i} X(i)
$$


Table 1. Fundamental operations of Differential Transformation method (DTM) [20]

\begin{tabular}{|c|c|}
\hline Original function & Transformed function \\
\hline$x(t)=\alpha u(t)+\beta v(t)$ & $X(i)=\alpha U(i)+\beta V(i)$ \\
\hline$x(t)=\frac{d^{m} u(t)}{d t^{m}}$ & $X(i)=\frac{(i+m) !}{i !} U(i+m)$ \\
\hline$x(t)=u(t) v(t)$ & $X(i)=\sum_{l=0}^{i} U(l) V(i-l)$ \\
\hline$x(t)=t^{m}$ & $X(i)=\delta(i-m)=\left[\begin{array}{ll}1 & i=m \\
0 & i \neq m\end{array}\right.$ \\
\hline$x(t)=\exp (t)$ & $X(i)=\frac{1}{i !}$ \\
\hline
\end{tabular}

\section{SOLUTION METHODOLOGY WITH DIFFERENTIAL TRANSFORMATION METHOD (DTM)}

For the governing equation (refer Eq. 2), the differential transformation method has been implemented using the fundamental definition and principles as illustrated in Table 1. The transformed form of Eq. (2) can be expressed as follows:

$$
\left[\sum_{l=1}^{i}(i+2-l)(i+1-l) \phi(i+2-l)\right]+(i+1) \phi(i+1)-P^{2} \phi(i)=0
$$

In the above equation $\phi$ is the transformed function of $\theta$. The transformed boundary conditions are taken in the form below:

$$
\phi(1)=0
$$

and

$$
\sum_{i=0}^{\infty} \phi(i)=1
$$

From Eq. (11) for $i=0$, it yields

$$
\phi(1)=P^{2} \phi(0)
$$

For $i=1$ :

$$
\phi(2)=\frac{P^{2}}{4} \phi(1)
$$

By proceeding the same way, substituting Eqs. (14) and (15) into Eq. (10), we have obtained the closed form solution. 
The actual rate of energy transfer from the symmetric sector of the plate in dimensionless form can be written using Fourier's law of heat conduction as follows [5]:

$$
q=-\left.2 y_{s} z \frac{k}{L}\left(T_{1}-T_{0}-\frac{S}{2 U_{L}}\right) \frac{d \theta}{d X}\right|_{X=1}
$$

Using DTM, Eq. (16a) can be expressed as:

$$
Q_{a c t}=\frac{q}{k z\left(T_{1}-T_{0}-\frac{S}{2 U_{L}}\right)}=-\left.2 \psi \frac{d \theta}{d X}\right|_{X=1}=-2 \psi \sum_{l=1}^{\infty} l F(l)
$$

Following the principle of maximum possible energy transferred, the mathematical expression for the ideal rate of heat transfer can be written as [5]:

$$
Q_{i d e a l}=-\frac{2 B i}{\psi} \sqrt{1+\frac{\psi^{2}}{4}}
$$

The efficiency of the absorber plate can be written from the definition as [5]:

$$
\eta_{\text {Absorber }}=\frac{Q_{\text {act }}}{Q_{\text {ideal }}}=\frac{\sum_{l=1}^{\infty} l F(l)}{P^{2}}
$$

\section{RESULTS AND DISCUSSION}

In this paper, a steady state, 1-D heat transfer analysis has been studied. The analytical methodology represented in the current work has been validated in comparison with Modified Bessel's function. For this assignment, Fig. 2 has been drawn. Figure 2 shows the dimensionless temperature distribution in an absorber plate for various values of non-dimensional parameter ' $\mathrm{P}$ '. It is inevitable that the absorber plate temperature varies linearly along the heat flow direction. Also this temperature distribution determined by Bessel's function exactly matches with the result obtained from DTM analysis as depicted in Figure 2. The temperature curve gets steeper with increase of 'P'. The value of ' $\mathrm{P}$ ' has been selected from the design aspect of absorber plate. This analysis has presented a fine accuracy of DTM in comparison with the existing Modified Bessel's function with a series solution. Next an effort has been employed to estimate the temperature distribution in dimension form with variation of overall loss coefficients and in Figure 3 it can be clear that the temperature gradually decreases along the longitudinal direction in the symmetric sector of the absorber plate. Initial collector fluid temperature has been considered as $T_{1}=40^{\circ} \mathrm{C}$ and ambient temperature is $T_{0}=30^{\circ} \mathrm{C}$. In the present case the absorbed solar radiation in the plate has been taken as $S=600 \mathrm{~W} / \mathrm{m}^{2}$ arbitrarily. Naturally for higher overall loss coefficient, the temperature of the plate at the line of symmetry declines as depicted in Figure 3. In general, the local plate temperature reduces with an increase in overall loss coefficient. 


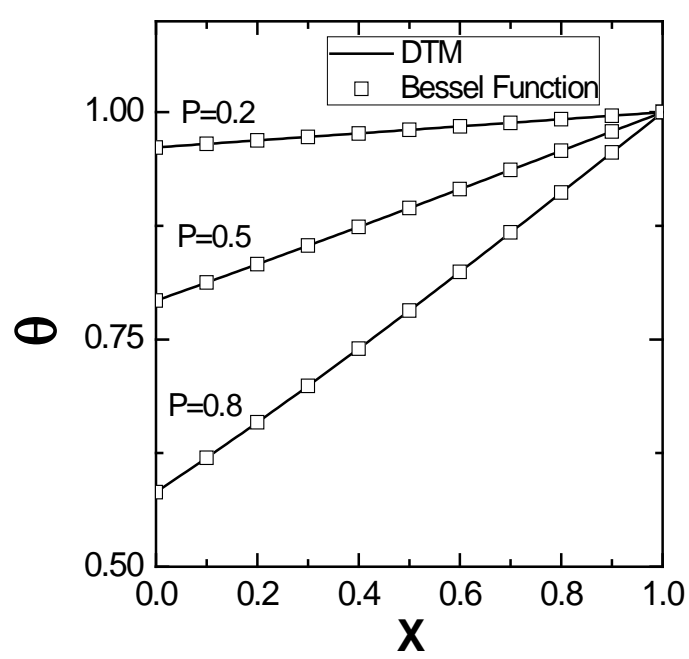

Figure 2. Comparisons of dimensionless temperature distribution in absorber plate predicted by differential transform method and modified Bessel function

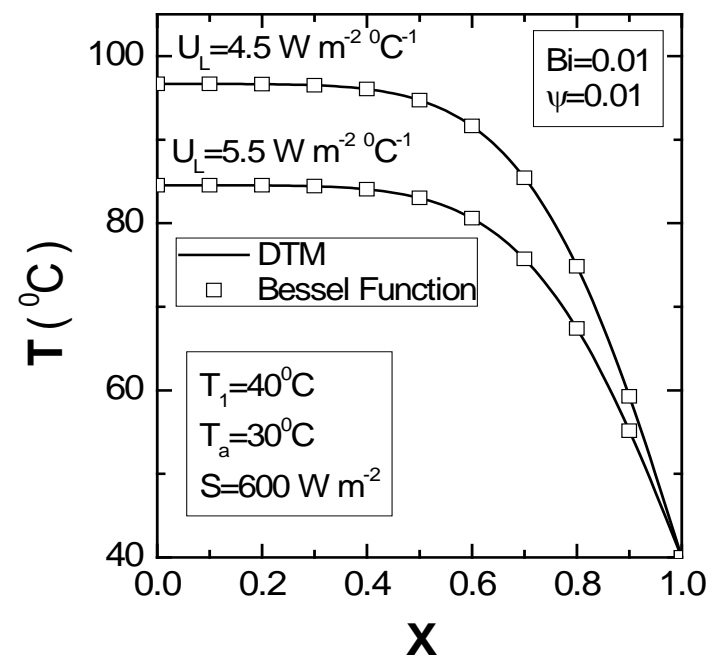

Figure 3. Effects of overall loss coefficients on dimensional temperature of absorber plate

Figure 4 illustrates the variation of temperature along the longitudinal direction for different values of absorbed solar radiation. Solar radiation passing through glazing is absorbed directly through the absorber plate without any intermediate reflection. The surface coatings done on the plate are highly absorptive property for short wavelength of light. Keeping the thermophysical properties same as taken in Figure 3, the temperature shows a high value than the ambient value due to a higher value of absorbed solar radiation $\left(\mathrm{S}=600 \mathrm{~W} / \mathrm{m}^{2}\right)$. As the incident absorbed energy increases, temperature of the plate also increases but a uniform variation is not found. Initially this trend is linear and then it decreases slowly for keeping a constant base temperature. For this study, Biot number is considered as $\mathrm{Bi}=0.01$. In this investigation, DTM and Modified Bessel's function have also shown a well agreement to each other.

Figure 5 demonstrates the dependence of Biot number $(\mathrm{Bi})$ on the temperature distribution of the absorber plate. $\mathrm{Bi}$ is considered a less value due to small conductive resistance of absorber plate. As Bi decreases, temperature steadily drops. 
Figure 6 depicts the temperature distribution for different aspect ratio $(\psi)$ of the absorber plate. It has been shown that for $\psi=0.01$, there is a negligible variation of plate temperature along the heat flow direction from the starting coordinate $\mathrm{x}$ and then it decreases gradually. Aspect ratio is a geometrical parameter which has strong influence on thickness as well as length of the plate. For $\psi=0.05$ the temperature profile becomes almost a linear. Thus to select the geometrical constraints in a practical design this result is very much helpful in terms of thermal aspects.

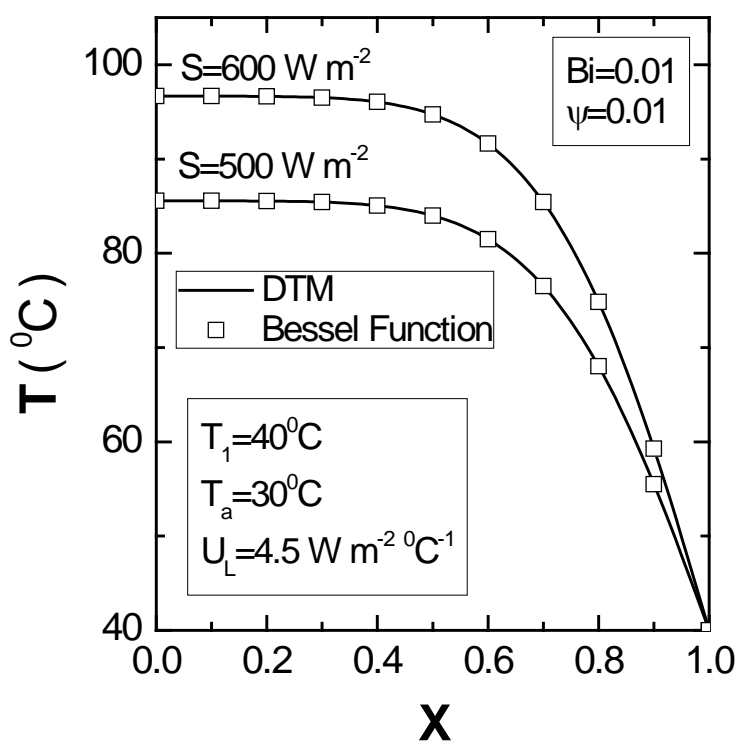

Figure 4. Absorber plate temperature as a function of absorbed solar flux

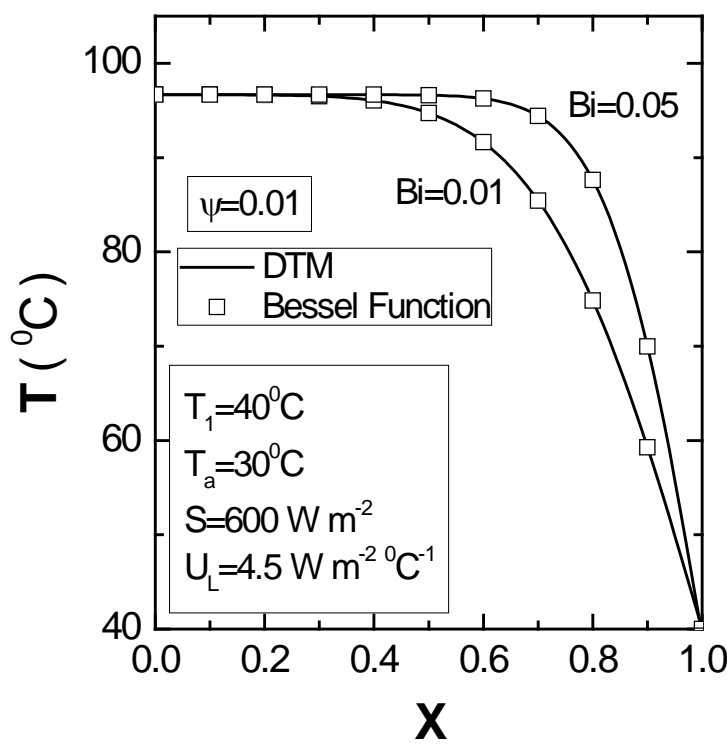

Figure 5. Influences of Biot number on temperature of absorber plate 


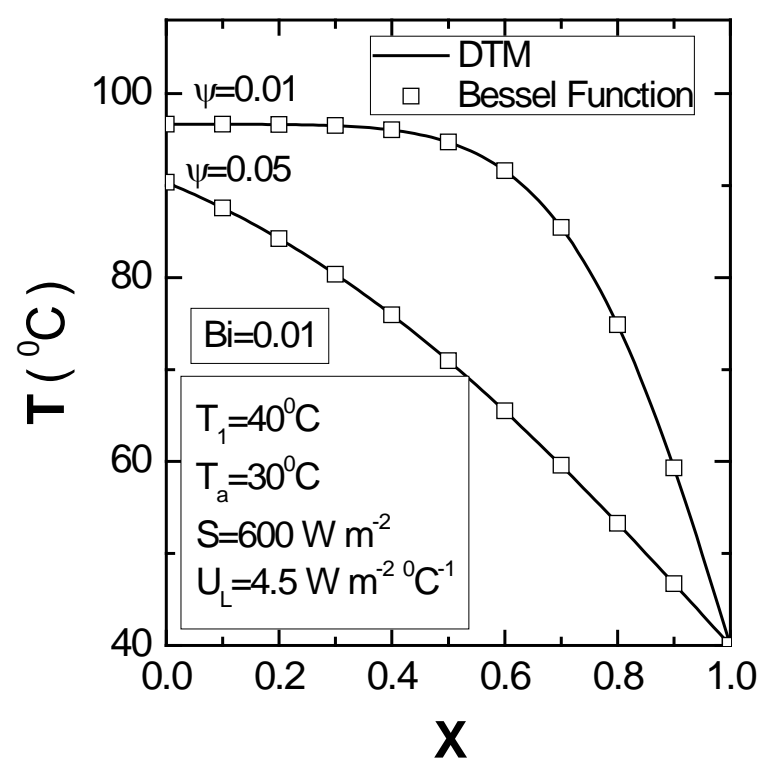

Figure 6. Absorber plate temperature as a function of geometrical parameter

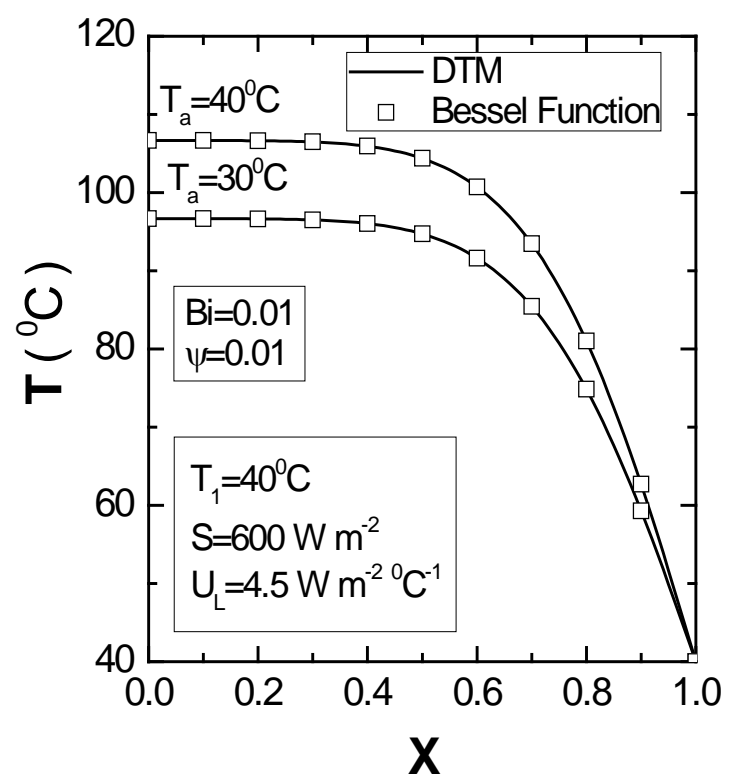

Figure 7. The influence of surrounding temperature on absorber plate temperature

In Figure 7, the effect of ambient temperature on the absorber plate temperature has been studied. For collector fluid inlet temperature $T_{1}=40^{\circ} \mathrm{C}$, the graphical analysis has been carried out at two different ambient temperatures. It is clear that for higher value of $T_{a}$, peak temperature at the midpoint of the plate between two fluid carrying tubes is increasing. This result can be useful to define the atmospheric condition of the solar collector which must be operated in specified working conditions while other properties kept constant as previous cases. 


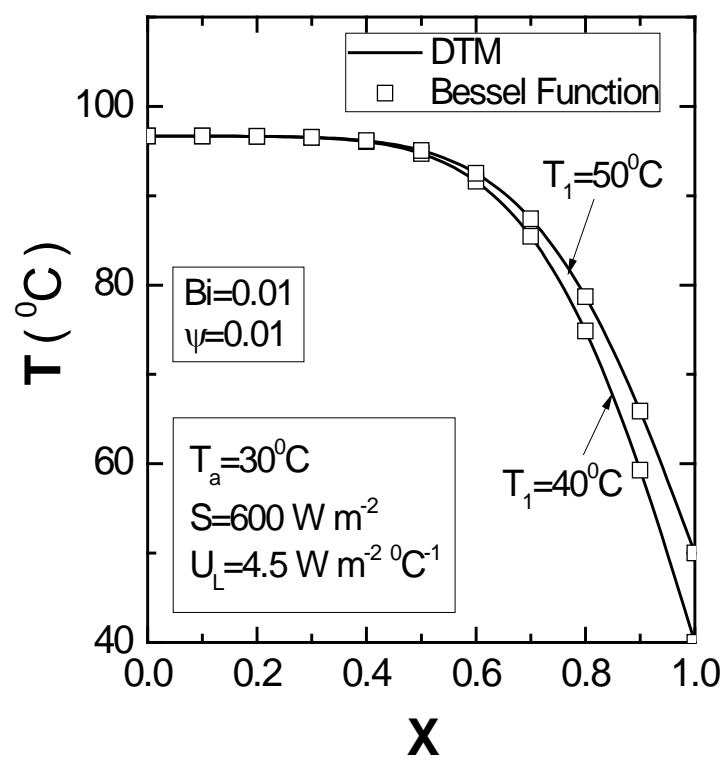

Figure 8 Dependency of absorber plate temperature on collector fluid temperature

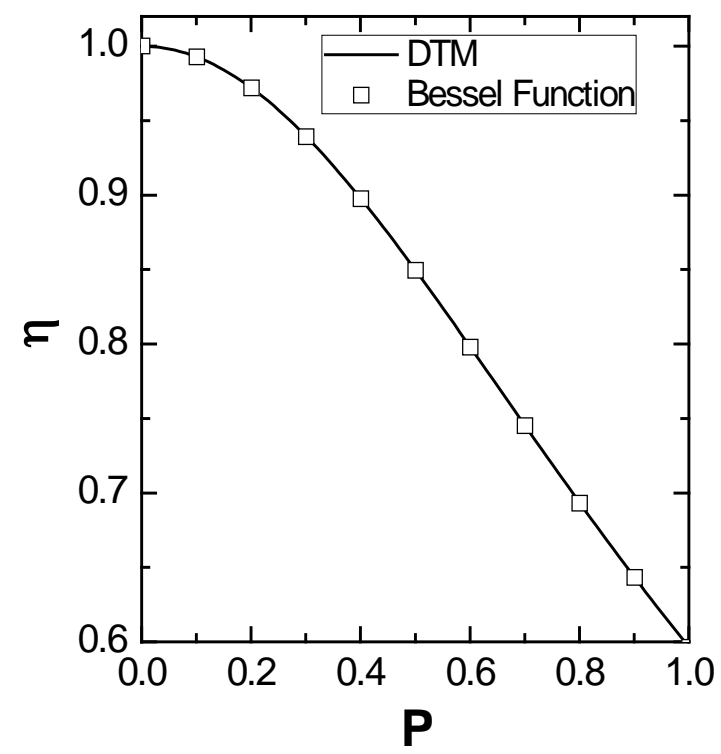

Figure 9 Plate efficiency $\eta$ as a function of thermophysical and geometric parameter ' $\mathrm{P}$ '

In Figure 8, the temperature profile for triangular absorber plate is eventually same as depicted in Figure 7 for different ambient temperature. In this case temperature distribution of absorber plate for two different collector fluid inlet temperatures has been studied. It is actually opposite representation of the aspect mentioned in Figure 7. The ambient temperature is kept constant as $T_{0}=30^{\circ} \mathrm{C}$. Initially at the symmetric section, the temperature is high and gradually it lowers towards the plate adjacent to the fluid carrying tube. This profile may help for selection of the collector fluid temperature to provide a smooth operation of the collector. Efficiency of the absorber plate is very influential parameters to quantify the performance of the solar collector. In the present analysis based on DTM the efficiency of the absorber plate has been expressed in Eq. (16d). On that basis the efficiency has been determined and 
this result is plotted in Figure 9 as a function of $P$. From this figure, it shows that the efficiency $(\eta)$ is a maximum for the lowest value of geometric parameter $P$ and it decreases with the increment of ' $P$ '. Both DTM and Bessel function have provided a well integrity in the analysis. Here it may be noted that a decrease in $\mathrm{P}$ reduces the conductive resistance of the plate. Therefore, this effect amplifies the plate efficiency.

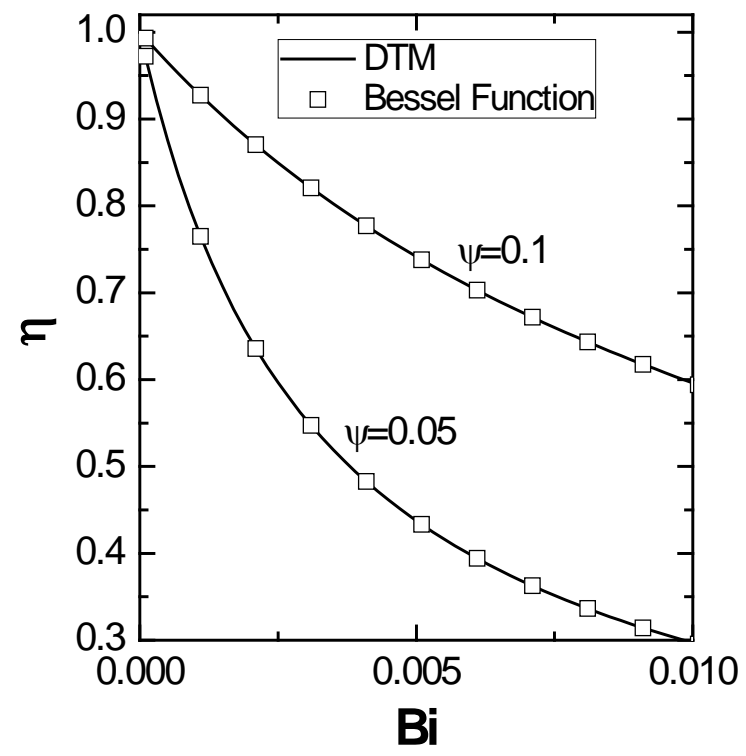

Figure 10 Variation of $\mathrm{Bi}$ and $\eta$ on plate efficiency

A parametric study has been carried out to judge the variation of Biot number with plate efficiency for different $\psi$ in Fig. 10. With the increasing rate of $\mathrm{Bi}$, efficiency $\eta$ decreases. Also it has been predicted that for a lower value of aspect ratio $\psi=0.05$ curve becomes steeper in comparison with $\psi=0.1$. At a higher value of $\psi$, the efficiency curve becomes gradually decreasing in nature while for a lower $\psi$ it steadily drops. Thus this result can be effective for optimizing the efficiency of absorber plate with respect to the influence of the aspect ratio.

\section{CONCLUSION}

From the present research work the following concluding remarks can be drawn:

- A convenient analytical method established by DTM is proposed to find out the temperature and its relevant functional parameters of a triangular profile flat plate solar collector. The present methodology is suitable for the analysis of absorber plate of any shape under an actual design condition.

- The analysis is presented for 1-D steady state condition and it has been verified with Modified Bessel's function which exactly matches with the analytical solution.

- The fin efficiency has been easily determined with a closed form solution obtained for the temperature distribution. For the large aspect ratio $(\psi)$ the fin efficiency becomes less steep. Also thermo-geometric parameter $(\mathrm{P})$ has a high influence on the effective design of an absorber plate.

- This research work has been carried out for the variable thickness absorber plate due to effective utilization of the plate material for transferring energy to the collector fluid.

- From the research output, the absorber plate efficiency can be determined without any calculation from the known design condition.

- Finally, DTM is implemented successfully to analyse the absorber plate in solar flat-plate collector for the first time. 


\section{NOMENCLATURE}

$\mathrm{b}$

$\mathrm{Bi}$

$\mathrm{F}(\mathrm{l})$

$\mathrm{H}$

i

$\mathrm{k}$

L

$\mathrm{P}$

q

Qact

Qideal

$\mathrm{S}$

$\mathrm{t}, \mathrm{t}_{\mathrm{i}}$

$\mathrm{T}$

$\mathrm{T}_{\mathrm{a}}$

$\mathrm{T}_{1}$

$\mathrm{U}_{\mathrm{L}}$

$\mathrm{x}$

$\mathrm{x}(\mathrm{t})$

$\mathrm{X}(\mathrm{i})$

$\mathrm{X}$

$\mathrm{y}_{\mathrm{s}}$

$\mathrm{z}$

Greek symbols

$\theta$

$\psi$

$\eta_{\text {absorber }}$

$\Phi$

$\alpha, \beta$ and $\delta$ thickness of the solar absorber plate adjacent to the fluid carrying tube (m) $d_{p}$

Biot No. $h L / k$

function for analyzing DTM

constant functional parameter of DTM

non-negative integers, $0,1,2 \cdots$

thermal conductivity of solar absorber plate $\left(\mathrm{Wm}^{-10} \mathrm{C}^{-1}\right)$.

length of the solar absorber plate (m)

dimensionless thermo-physical constant, $P=\sqrt{B i \sqrt{\left(1+\psi^{2}\right)} / \psi^{2}}$

rate of heat transfer from the plate to the fluid carrying tube (W)

dimensionless actual rate of heat transfer

dimensionless ideal rate of heat transfer

absorbed solar radiation flux on the absorber plate $\left(\mathrm{Wm}^{-2}\right)$

anonymous points in the solution domain

local temperature of the absorber plate $\left({ }^{\circ} \mathrm{C}\right)$

ambient temperature adjacent to the absorber plate $\left({ }^{\circ} \mathrm{C}\right)$

absorber plate temperature adjacent to the fluid carrying tube $\left({ }^{\circ} \mathrm{C}\right)$

overall heat loss coefficient $\left(\mathrm{Wm}^{-2 \circ} \mathrm{C}^{-1}\right)$

spatial coordinate along the heat transfer direction in absorber plate (m)

anonymous function of DTM

transformed function of $x(t)$

non-dimensional spatial length along the $x$ direction, $x / L$

maximum thickness of the absorber plate $(\mathrm{m})$

width of the solar absorber plate (m)

dimensionless temperature, $\left(T-T_{0}-\frac{S}{2 U_{L}}\right) /\left(T_{1}-T_{0}-\frac{S}{2 U_{L}}\right)$

aspect ratio, $y_{S} / L$

efficiency of solar absorber, $Q_{a c t} / Q_{\text {ideal }}$

transformed function of $\theta$

anonymous constants utilized in transformed function of DTM

\section{REFERENCES}

[1] Duffie JA, Beckman WA. Solar Engineering of Thermal Processes. 2nd ed. New York: John Wiley \& Sons; 1991.

[2] Hollands KGT, Stedman BA. Optimization of an absorber plate fin having a step change in local thickness. Solar Energy 1992; 49: 493-495. https://doi.org/10.1016/0038-092X(92)90157-6.

[3] Ong KS. Thermal performance of solar air heaters: mathematical model and solution procedure. Solar Energy 1995; 55(2): 93-109. https://doi.org/10.1016/0038-092X(95)00021-I.

[4] Ong KS. Thermal performance of solar air heaters-experimental correlation. Solar Energy 1995; 55(3): 209-217. https://doi.org/10.1016/0038-092X(95)00027-O.

[5] Kundu B. Performance analysis and optimization of absorber plates of different geometry for a flat-plate solar collector: a comparative study. Appl Therm Eng 2002; 22: 999-1012. https://doi.org/10.1016/S13594311(01)00127-2.

[6] Dhariwal SR, Mirdha US. Analytical expressions for the response of flat-plate collector to various transient conditions. Energy Conv Manag 2005; 46 (11-12): 1809-1836. https://doi.org/10.1016/j.enconman.2004.08.008.

[7] Badescu V. Optimum size and structure for solar energy collection systems. Energy 2006; 31: 1819-1835. https://doi.org/10.1016/j.energy.2005.09.008.

[8] Gao W, Lin W, Liu T, Xia C. Analytical and experimental studies on the thermal performance of cross-corrugated and flat plate solar sir heaters. Appl Energy 2007; 84 (4): 425 - 441. https://doi.org/10.1016/j.apenergy.2006.02.005.

[9] Kundu B. Performance and optimum design analysis of an absorber plate fin using recto-trapezoidal profile. 
Solar Energy 2008; 82: 22- 32. https://doi.org/10.1016/j.solener.2007.05.002.

[10] Ho CD, Yeh HM, Cheng TW, Chen TC, Wang RC. The influences of recycle on performance of baffled doublepass flat-plate solar air heaters with internal fins attached. Appl Energy 2009; 86: 1470-14788. https://doi.org/10.1016/j.apenergy.2008.12.013.

[11] Kundu B. Analytic method for thermal performance and optimization of an absorber plate fin having variable thermal conductivity and overall loss coefficient. Applied Energy 2010; 87: $2243-2255$. https://doi.org/10.1016/j.apenergy.2010.01.008.

[12] El-Sebaii AA, Aboul-Enein S, Ramadan MRI. Thermal performance investigation of double pass-finned plate solar air heater. Applied Energy 2011; 88: 1727-1739. https://doi.org/10.1016/j.apenergy.2010.11.017.

[13] Kundu B, Lee K.-S. Fourier and non-Fourier heat conduction analysis in the absorber plates of a flat-plate solar collector. Solar Energy 2012; 86: 3030 - 3039. https://doi.org/10.1016/j.solener.2012.07.011.

[14] Subiantoro A, Ooi KT. Analytical models for the computation and optimization of single and double glazing flat plate solar collectors with normal and small air gap spacing. Applied Energy 2013; 104 : 392 - 399. https://doi.org/10.1016/j.apenergy.2012.11.009.

[15] Bracamonte J, Baritto M. Optimal aspect ratios for non-isothermal flat plate solar collectors for air heating. Solar Energy 2013; 97: 605 - 613. https://doi.org/10.1016/j.solener.2013.09.007.

[16] Eismann R. Accurate analytical modelling of flat plate solar collectors: Extended correlation for convective heat loss across the air gap between absorber and cover plate. Solar Energy 2015; 122: 1214 - 1224. https://doi.org/10.1016/j.solener.2015.10.037.

[17] Sun C, Liu Y, Duan C, Zheng Y, Chang H, Shu S. A mathematical model to investigate on the thermal performance of a flat plate solar air collector and its experimental verification. Energy Conv Manag 2016; 115: 43 - 51. https://doi.org/10.1016/j.enconman.2016.02.048.

[18] Diego-Ayala U, Carrillo JG. Evaluation of temperature and efficiency in relation to mass flow on a solar flat plate collector in Mexico. Renew Energy 2016; 96: 756 - 764. https://doi.org/10.1016/j.renene.2016.05.027.

[19] Tiwari GN. Solar Energy Fundamentals, Design, Modeling and Applications. 247, Narosa Publishing House; 2002.

[20] Zhou JK. Differential Transformation Method and its Application for Electrical Circuits. Hauzhang University Press, Wuhan (China); 1986.

[21] Abbasov A, Bahadir AR. The investigation of the transient regimes in the nonlinear systems by the generalized classical method. Math Prob Eng 2005; 5: 503-519. http://dx.doi.org/10.1155/MPE.2005.503.

[22] Rashidi MM, Laraqi N, Sadri SM. A novel analytical solution of mixed convection about an inclined flat plate embedded in a porous medium using the DTM-Padé. Int J Them Sci 2010; 49(12): $2405-2412$. https://doi.org/10.1016/j.ijthermalsci.2010.07.005.

[23] Ghafoori S, Motevalli M, Nejad MG, Shakeri F, Ganji DD, Jalaal M. Efficiency of differential transformation method for nonlinear oscillation: comparison with HPM and VIM. Current Appl Phys 2011; 1: 965-971. https://doi.org/10.1016/j.cap.2010.12.018.

[24] Kundu B, Lee K.-S. A proper analytical analysis of annular step porous fins for determining maximum heat transfer. Energy Conv Manag 2016; 110: 469-480. https://doi.org/10.1016/j.enconman.2015.09.037.

[25] Yaghoobi H, Torabi M. The application of differential transformation method to nonlinear equations arising in heat transfer. Int Commun Heat Mass Transf 2011; 38: 815-820. https://doi.org/10.1016/j.icheatmasstransfer.2011.03.025.

[26] Dogonchi AS, Ganji DD. Convection-radiation heat transfer study of moving fin with temperature-dependent thermal conductivity, heat transfer coefficient and heat generation. Appl Them Eng 2016; 103 : 705 - 712. https://doi.org/10.1016/j.applthermaleng.2016.04.121.

[27] Bervillier C. Status of the differential transformation method. Appl Math Comp 2012; 218 : $10158-10170$. https://doi.org/10.1016/j.amc.2012.03.094. 